J. Grimond urged the increase of Government aid to such organizations as Voluntary Service Overseas, while recognizing that this was no substitute for technical aid. However, in replying on the debate the Secretary of State for Industry, Trade and Regional Development, Mr. E. Heath, made little reference to either technical assistance or voluntary service and Mr. Wilson was the only speaker to refer to overseas research.

\title{
AIDS TO TEACHING UNIVERSITY PHYSICS
}

$\mathrm{T}$ $\mathrm{HE}$ university teacher of physics at present is having to $\operatorname{cope}$ not only with a rapidly growing and much expanded subject, but also with the increased demands on his time, on apparatus and on accommodation, because of larger numbers of students. The many new text-books dealing with the advances during recent years are very often limited to narrow fields, and invaluable though they are to the postgraduate student embarking on research or to the specialist, they are of little help to the undergraduate teacher. Because of financial stringency he may not be able to purchase what he requires of these new texts, and even with access to the books, he will find it most difficult to devote adequate time to their detailed. study. He needs assistance in the appropriate selection of material not only for himself, but also in order to advise his students how to avoid the inessential so that the student may still get a good grounding in basic classical physics and yet also become acquainted with recent investigations and problems. Little or nothing so far has been done in Britain to help the university teacher in his attempts to modify and improve the content of undergraduate courses, but in the United States the Association of Physies Teachers has a committee under the chairmanship of Prof. Arons which, with the support of the National Seience Foundation, is actively engaged on this work.

The committee publishes a series of "Resource Letters", which are initially printed in the American Journal of Physics. These have included Letters on plasma physies ( $P P-1$, July 1961); polarized light ( $P L-1$, Oetober 1961); the Mossbauer effect ( $M E-1$, January 1963); kinematics and dynamies of satellite orbits (SO-1, April 1963) and quantum and statistical aspects of light (QSL-1, May
1963). Each Letter consists of a list of references to books and articles on the subject, divided into sections according to particular aspects and introduced by explanatory notes. The Letter always includes references to, or deseriptions of, laboratory experiments and demonstrations and how the appropriate apparatus may be made or where it may be obtained, together with the titles of films or other illustrative material suitable for use by the teacher or students. No Resource Letter is meant to be exhaustive and complete, and in time there may be more than one Letter on some of the main subjects of interest.

To save time in reference to periodicals, and to assist those who do not have easy access to libraries, a series of reprint books each dealing with one of the subjects of the Letters and containing a copy of the Resource Letter together with reprints of a selected few of the articles listed in the Letter have now been published for purchase by the American Institute of Physies*. The set of booklets have already received a warm welcome in the United States, and indeed a second printing of one of them has been required. They will be equally welcomed in Britain and no university physics department should be without several copies of them for use by the staff engaged in undergraduate teaching. The American Association of Physics Teachers is to be congratulated on this valuable pioneering effort and for its foresight in tackling an important and urgent problem in present-day higher education.

S. WEINTROUB * Plasma Physics-Selected Reprints. Pp. 119. Polarized Light-Selected
Reprints. Pp. 103. Mossbauer Effect-Selected Reprints. Pp. 127. Kinematics and Dynamics of Satellite Orbits-Selected Reprints. Pp. 108. Quantum and and Dynamics of Satellite Orbits--Selected Reprints. Pp. 108. Quantum and Statistical Aspects of Light-Selected Reprints. Pp. 92. New York: American
Institute of Physics. Published for the American Association of Physics Teachers, 1963.) 2 dollars each.

\section{IODINE-|3| FALL-OUT IN MILK}

"I ODINE and milk don't mix": so read the placard carried by a schoolgirl protesting against the proposal to build a nuclear plant in California. So familiar are we with the problem of contamination of milk with iodine-131 from fall-out that there is no need to emphasize the importance of any new assessment of the effect of nuclear-weapon tests on levels of iodine-131 in milk and on the consequent radiation dose delivered to the thyroid glands of those who drink fresh milk. Such assessments inevitably begin by treating the relationship between the amount of fall-out deposited and subsequent levels of iodine-131 in milk. A direct investigation of this relationship in the field ideally requires a situation such that deposition of radioactive material takes place at either a constant rate or over a short period. The latter condition is met within the area of local fall-out from a nuclear test. Dr. H. A. Knapp has endeavoured to make use of measurements made in connexion with the $S M A L L B O Y$ low-yield, ground burst of $1962 *$.

'The investigation is retrospective and hence has inherent limitations. Milk from two dairies 50-100 miles from ground zero and from an area in north-east Utah. some 300 miles downwind had been analysed for iodine131. The fall-out pattern had been followed by measuring

* Yodine-131 in Fresh Milk and Human Thyroids Following a Single Deposition of Nuclear Test Fallout. By H. A. Knapp. U.S.A.E.C. Document No. TID-19266. Pp. 106. (Washington, D.C.: Office of Technical Service, Dept. of Commerce, 1963.) levels of $\gamma$-radiation over the ground surface although not in the immediate locality of the areas grazed by cattle. By making assumptions with regard to the mode of decay of activity, Dr. Knapp has developed an empirical relationship between the level of $\gamma$-radiation from fission products deposited at $24 \mathrm{~h}$ after detonation and the maximum concentration of iodine-131 in milk and has then extended this to cover the radiation dose received by the thyroid glands of people drinking fresh milk. Unfortunately the $\gamma$-radiation measurements were made with relatively insensitive survey instruments which, although quite adequate for the purpose of overall evaluation of external exposure to $\gamma$-radiation-for which they were intended-are insufficiently accurate to give a true indication of the ground deposition: examination of the readings listed in the report reveals that many were only a few times the assumed average background-lovel. For this and other reasons, Dr. Knapp's interpretation of the data has been under fire from an expert committee convened to review his report. The committee's-somewhat adverse-opinions are included as as preface. The fact remains that the relationship obtained by Dr. Knapp accords remarkably well with what might be expected on theoretical grounds and that, where it was possible to compare predicted thyroidal iodine-131 burdens with actual burdens measured in vivo, when allowance is made for more recent information than was available to Dr. Knapp on the 